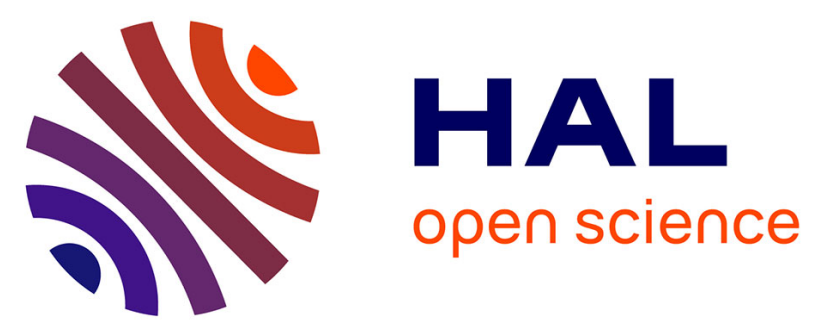

\title{
Does the severity of obesity influence bone density, geometry and strength in adolescents?
}

Valérie Julian, Grace O’Malley, Lore Metz, Daniel Weghuber, Daniel Courteix, Alicia Fillon, Yves Boirie, Martine Duclos, Bruno Pereira, David Thivel

\section{- To cite this version:}

Valérie Julian, Grace O'Malley, Lore Metz, Daniel Weghuber, Daniel Courteix, et al.. Does the severity of obesity influence bone density, geometry and strength in adolescents?. International Journal of Pediatric Obesity, 2021, 16 (12), pp.e12826. 10.1111/ijpo.12826 . hal-03312957

\section{HAL Id: hal-03312957 https://hal.uca.fr/hal-03312957}

Submitted on 18 Feb 2022

HAL is a multi-disciplinary open access archive for the deposit and dissemination of scientific research documents, whether they are published or not. The documents may come from teaching and research institutions in France or abroad, or from public or private research centers.
L'archive ouverte pluridisciplinaire HAL, est destinée au dépôt et à la diffusion de documents scientifiques de niveau recherche, publiés ou non, émanant des établissements d'enseignement et de recherche français ou étrangers, des laboratoires publics ou privés.

\section{(ㅇ)(1) $\$$}

Distributed under a Creative Commons Attribution - NonCommerciall 4.0 International 


\section{Does the severity of obesity influence bone density, geometry and strength in adolescents?}

Valérie Julian ${ }^{1,4}$, Grace O’Malley ${ }^{2}$, Lore Metz $^{3}$; Daniel Weghuber ${ }^{4}$, Daniel Courteix ${ }^{3}$, Alicia Fillon ${ }^{3}$, Yves Boirie ${ }^{5}$, Martine Duclos ${ }^{1}$, Bruno Pereira ${ }^{6}$ David Thivel ${ }^{3}$

${ }^{1}$ Department of Sport Medicine and Functional Explorations, University Teaching Hospital of Clermont-Ferrand, Diet and Musculoskeletal Health Team, CRNH, INRA, University of Clermont Auvergne, Clermont-Ferrand, France

${ }^{2}$ School of Physiotherapy, RCSI University of Medicine and Health Sciences, Dublin; W82GO Child and Adolescent Weight Management Service, Children's Health Ireland at Temple Street, Dublin, Ireland.

${ }^{3}$ Laboratory AME2P, University of Clermont Auvergne, Aubière, France

${ }^{4}$ Department of Pediatrics, Paracelsus Medical School, Salzburg, Austria

${ }^{5}$ Department of Clinical Nutrition, University Teaching Hospital of Clermont-Ferrand, Diet and Musculoskeletal Health Team, CRNH, INRA, University of Clermont Auvergne, Clermont-Ferrand, France

${ }^{6}$ Department of Biostatistics, University Teaching Hospital of Clermont-Ferrand, ClermontFerrand, France

Keywords: Childhood obesity; Body mass index; Bone mineral density; Trabecular bone score

Running title: Bone density, geometry and strength in regards to the severity of obesity 
Acknowledgements: Author contributions: VJ and DT design the work and wrote the manuscript. VJ, AF and DT contribute to data collection. BP performed the data analysis. GO, ML, DW, DC, YB and MD contributed to manuscript read or revising it critically. All authors approved the submitted version.

*Address of corresponding author: Valérie JULIAN, M.D., Ph.D., Department of Sport Medicine and Functional Explorations, University Teaching Hospital, Clermont-Ferrand, 58 rue Montalembert, 63000 Clermont-Ferrand, FRANCE

tel: +(33) 473751888 fax: +(33) 473751661 E-mail: vjulian@ chu-clermontferrand.fr

Conflict of interest: No conflicts of interest was declared.

\section{ABSTRACT}

Background: Relationships between the severity of obesity and bone health remain underexplored.

Objectives: To compare whole-body and localized bone mineral content (BMC) and density (BMD), trabecular bone score (TBS) and hip geometry and strength between adolescents with obesity $v s$ extreme obesity.

Methods: This cross-sectional study included 154 adolescents (12-15y, 62\%females) who were classified as having obesity $\left(\mathrm{OG},\left[95^{\text {th }}-99^{\text {th }}\right]\right.$ percentile) or extreme obesity $\left(E O G,>99^{\text {th }}\right.$ percentile). Fat mass (FM), lean mass (LM), BMC, BMD for total-body-less-head (TBLH), lumbar spine (LS), hip, TBS and geometric and strength indices at the narrow-neck (NN), femoral shaft (FS) and intertrochanteric regions (IT) were assessed by Dual-X-ray Absorptiometry (DXA).

Results: There was no significant sex-interaction. For both sexes, TBLH BMC and BMD were not different between groups. TBS was lower in EOG compared with OG in both sexes in 
univariate analysis and after adjustment with maturation and body weight ( $\mathrm{p}<0.05)$. Hip BMD was significantly higher in the EOG compared to OG only after adjustment with maturation and fat mass percentage ( $\mathrm{p}<0.05$ for men, $\mathrm{p}<0.01$ for women). For both sexes, TBLH, LS and hip BMC and BMD positively correlated with weight, BMI, LM and FM. TBS negatively correlated with BMI-percentile in both sexes, with a negative correlation with FM for males only. Hip BMC and BMD, BMD, ACT and CSA at the 3 hip sites positively correlated with BMI-percentile in males.

Conclusions: Extreme obesity impacts bone health depending on anatomical sites, altering lumbar trabecular bone in both males and females adolescents. 


\section{INTRODUCTION}

Obesity is defined as an excessive accumulation of body fat resulting from an imbalance between energy intake and energy expenditure and is influenced by a multitude of biological, cultural, political, environmental and economic drivers ${ }^{1}$. Pediatric obesity is today a major worldwide concern due to its association with the development of early metabolic, physical and certain psychosocial comorbidities ${ }^{2,3}$ but also since approximately $80 \%$ of adolescents with obesity will continue to have obesity into adulthood ${ }^{4}$. Bone health has been lately considered in the context of obesity, and the obesity-related excess body weight initially mainly considered as having protective mechanical effects. It later became however apparent that fat accumulation would compromise bone mass and quality ${ }^{5-7}$, altering bone parameters 6,8 and potentially inducing a high risk of fracture, also in children and adolescents who are going through a crucial period for bone mineral acquisition ${ }^{9-12}$. Fat mass (FM) can negatively influence bone tissue by non-mechanical mechanisms, including via hormonal and cytokine signaling ${ }^{6}$. Importantly, patients with obesity could be even more prone to bone fragility in response to weight loss interventions that favor bone breakdowns ${ }^{13}$ due to a decreased mechanical loading on the skeleton, decreased caloric intake ${ }^{5}$ and altered secretion of some key hormones and peptides involved in bone regulation ${ }^{7,14}$. Specifically, adolescents with obesity are less likely to participate in moderate to vigorous physical activity than their lean counterparts ${ }^{15}$. Furthermore, they are susceptible to present certain nutritional deficits known to alter bone density ${ }^{16}$.

One study found an association between higher levels of adiposity and lower whole-body bone mineral density (BMD) in both female mice ranging from lean to overweight, and postmenopausal women ranging from overweight to extreme obesity, suggesting that obesity may increase the risk of osteoporosis. Similarly, whole-body BMD correlated negatively with the percentage of fat mass (FM) and positively with lean mass (LM) in women with morbid 
obesity (mean aged 46 years old) ${ }^{17}$. This potential impact of the severity of obesity on bone parameters remains however controversial. Indeed, in a recent cross-sectional study, the severity of obesity (assessed by BMI international classification) did not seem impact wholebody BMD values in women during the premenopausal period and who were classified as with severely obesity (Class II, BMI between 35 and $39.9 \mathrm{~kg} / \mathrm{m}^{2}$ ), morbid obesity (class III, BMI between 40 and $50 \mathrm{~kg} / \mathrm{m}^{2}$ ) and super morbid obesity (class III, with BMI $>50 \mathrm{~kg} / \mathrm{m}^{2}$ ) ${ }^{18}$.

While the relationship between the severity of obesity (or rather the influence of body size) and bone health remains to be fully clarified in adults, it is underexplored in the pediatric population. As previously shown, children with obesity have a lower whole-body BMD compared with children of healthy weight ${ }^{11,19}$. Likewise, a recent study carried out among 12-16 years old adolescents with obesity also reported lower multi-site BMD and hip geometric and strength values when adjusted for body weight, body fat mass or lean mass in comparison with maturation-matched adolescents who were lean, using dual X ray absorptiometry (DXA) with hip structural analysis (HSA) ${ }^{12}$. To our knowledge, Mosca et al. conducted the only study that explored the relationship between bone parameters and the severity of obesity (assessed by BMI international classification) among adolescents, showing lower whole-body BMD in female adolescents with normal weight in comparison with female adolescents with overweight (BMI between $85^{\text {th }}$ and $95^{\text {th }}$ percentiles), obesity (BMI $>$ between $95^{\text {th }}$ and $99^{\text {th }}$ percentile) and extreme obesity $\left(\mathrm{BMI}>99^{\text {th }}\right.$ percentile), which was not the case for males. Nevertheless, the population studied was rather heterogeneous considering age and maturation (with children aged between 10 to 19 years old) and the difference for whole-body BMD was not significant between the group with obesity and the group with extreme obesity ${ }^{20}$. Furthermore, while the impact of body composition on bone parameters and fracture risk would depend on the skeletal site ${ }^{9}$, it seems relevant to evaluate the impact of the severity of obesity on extensive bone parameters including not only whole- 
body, lumbar spine, but also total hip geometric indices of hip bone strength, and an indicator of microarchitecture as determined by the trabecular bone score (TBS), which has never been explored so far in adolescents with obesity.

In that context, the main aim of the present study was to compare whole-body and localized bone content and density as well as TBS and hip bone geometry and strength between adolescents with obesity or extreme obesity. The second aim was to investigate the most important determinants of bone parameters in this population.

\section{PARTICIPANTS AND METHODS}

\subsection{Subjects}

This study included 154 Caucasian adolescents with obesity (95 females, 59 males), who participated in a multidisciplinary weight loss program in two pediatric obesity centers (Children Medical Centre for Adolescents with Obesity, La Bourboule, France, and Pediatric Medical Center, Romagnat, France) between 2015 and 2018. Patients met the following criteria: (1) 12-16 years old, (2) BMI $>95^{\text {th }}$ percentile according to the international cut-off points, (3) Tanner stage 3-5, (4) regular menstruations for females, (5) no medication, no oral contraceptives, no hormone replacement therapy, no supplemental calcium and/or iron during the last 12 months, no regular tobacco or alcohol; (6) no major orthopedic problems, (7) steady weight with no diet program during the last 6 months, (8) no regular physical activity (<10MET-h/week, measured with the International Physical Activity Questionnaire). All the adolescents underwent a full medical examination (including Tanner's staging). Written informed consent was obtained from all individual participants included in the study and their parents. The trial has been conducted according to the Declaration of Helsinki principles and was approved by the relevant ethical committee (Comité de Protection des Personnes Est IV). This study combines data collected as part of distinct protocols conducted within the same 
clinical center and using the exact same methodology. These studies received ethical agreement (2015-A01024-45; 2017-A00817-46; AU1178) and were registered as clinical trials (clinicaltrial.gov; NCT02626273, NCT03466359, NCT02482220). No study effect was observed, allowing us to compute the data and perform the present single analysis.

\subsection{Anthropometric measurements}

Body mass $(\mathrm{kg})$ and height $(\mathrm{cm})$ were measured using a standard apparatus, to the nearest 0.1 $\mathrm{kg}$ and $0.5 \mathrm{~cm}$, respectively. BMI was calculated as body weight divided by height squared (kilogram per square meter). Adolescents were classified as having obesity (OG, $\left[95^{\text {th }}-99^{\text {th }}\right]$ percentile) or extreme obesity (EOG, $>99^{\text {th }}$ percentile), according to BMI curves, chronological age and sex (Center of disease control and prevention [CDC ${ }^{21}$.

\subsection{Body composition and bone measurements}

All subjects underwent DXA (Discovery A; Hologic Inc., Bedford, MA, USA) by a trained blinded technician for the assessment of body composition, bone densitometry assessment, TBS and hip structural analysis (HSA) (QDR-4500A DXA; Hologic, Bedford, MA, USA). Body composition data were analyzed using the Hologic QDR Software for Windows version 12.6 to assess total LM and FM for whole-body ${ }^{12}$.

Accordingly with the International Society for Clinical Densitometry (ISCD recommendations for adolescents ${ }^{22}, \mathrm{BMD}\left(\mathrm{g} / \mathrm{cm}^{2}\right)$ and BMC $(\mathrm{g})$ were determined at the total body less head (TBLH), lumbar spine (LS, L2-L4) and non-dominant hip. BMD measurements were converted to Z-scores ${ }^{23}$. The TBS, which is related to bone microarchitecture and fracture risk, was calculated using TBS iNsight software (Medimaps SA, France). The HSA was performed at the narrow neck (NN; narrowest part of the femoral neck), femoral shaft (FS; across the shaft $1.5 \mathrm{~cm}$ from the $\mathrm{NN}$ to the intersection of the neck and shaft axes), and the intertrochanteric region (IT; along the bisector of the angle of the axes of the NN and FS) (Figure 1). The following parameters were obtained: cross-sectional 
area $\left(\mathrm{CSA}\right.$, in $\mathrm{cm}^{2}$; index of resistance to axial forces), BMD $\left(\mathrm{g} / \mathrm{cm}^{2}\right)$, endocortical diameter $(\mathrm{ED}, \mathrm{cm})$, average cortical thickness $(\mathrm{ACT}, \mathrm{cm})$, width $(\mathrm{cm})$, cross-sectional moment of inertia (CSMI, $\mathrm{cm}^{4}$; estimate of resistance to bending forces in a cross-section), section modulus $\left(\mathrm{Z}, \mathrm{cm}^{3}\right.$; index of bending strength), and buckling ratio (BR; index of susceptibility to cortical buckling under compressive loads) ${ }^{12}$. Higher values are associated with greater predicted femoral strength for all HSA-derived parameters except BR, for which values are predictive of inferior strength ${ }^{24}$.

\subsection{Statistical analysis}

Continuous data were expressed as mean and standard-deviation. The assumption of normality was assessed with the Shapiro-Wilk test. The following variables did not meet the assumption of normality: weight, BMI, BMI percentile, LS BMC, hip BMC, NN BMD, NN CSA, NN CSMI, NN width, NN ED, NN ACT, NN BR, IT BMD, IT CSA, IT CSMI, IT width, IT ED, IT ACT, IT Z, IT BR, FS BMD, FS CSMI, FS BR, FM, LM. The comparisons between groups (i.e. between simple obesity group and extreme obesity group) were performed separately for each gender group using the Student t-test or the Mann-Whitney test when assumptions required for the t-test were not met. The homoscedasticity was analyzed using the Fisher-Snedecor test. The study of obesity level x gender interaction was analyzed using linear model with two in-between factors, sex and obesity level and their interaction. When appropriate, a log transformation was applied when variables were not normally distributed. Furthermore, this analysis (model 1) was completed by multivariable models adjusted on maturation (Tanner's stages) and weight (model 2) and with maturation (Tanner's stages) and percent body fat (model 3). The relationships between anthropometric measurements, body composition and bone parameters were explored using Pearson or Spearman correlation coefficient according to statistical distribution and applying a Sidak's type I error correction to take into account multiple comparisons. The statistical analysis was 
performed using Stata software version 15 (StataCorp, College Station, US). Statistical tests were two-sided with the type-I error set at $5 \%$.

\section{RESULTS}

\subsection{Clinical characteristics, total body less head, lumbar spine and total hip parameters}

TBLH BMD were $0.9 \pm 0.8 \mathrm{Z}$-score for females and 1.2 $\pm 1.1 \mathrm{Z}$-score for males. BMD at the lumbar site were $0.7 \pm 0.6 \mathrm{Z}$-score for females and $0.3 \pm 0.2 \mathrm{Z}$-score for males. Hip BMD were 1.0 $\pm 0.8 \mathrm{Z}$-score for females and $1.3 \pm 1.1 \mathrm{Z}$-score for males. The anthropometric measurements, body composition and bone parameters of adolescent females and males are presented respectively in Table 1 and Table 2. For both genders, TBLH BMD and BMC were not significantly different between EOG and OG. Nevertheless, TBS was lower in the EOG compared with the OG in both genders in univariate analysis $(\mathrm{p}<0.05)$ (model 1) and after adjustment with maturation and body mass ( $<$ <.05) (model 2), but not after adjustment with maturation and fat percentage (model 3). In both genders, at the lumbar site, BMD $(\mathrm{p}<0.01)$ and $\mathrm{BMC}(\mathrm{p}<0.001$ for females and $\mathrm{p}<0.01$ for males) were lower in the EOG compared with the OG after adjustment with maturation and body mass (model 2), which was not the case after adjustment with maturation and fat percentage (model 3). In males, BMD at the whole hip were significantly higher in the EOG compared to OG in multivariate analysis $(p<0.01)$ (model 1) and after adjustment with maturation and fat mass percentage ( $<<0.05$ for males) (model 3 ), which was not the case after adjustment with maturation and body mass (model 2). In females, BMD at the whole hip were significantly higher in the EOG compared to OG after adjustment with maturation and fat mass percentage $(\mathrm{p}<0.01)$ (model 3$)$.

\subsection{HSA parameters at the hip}

The HSA hip parameters of adolescent females and males are presented respectively in Table 1 and Table 2. For males, BMD, ACT and CSA were higher in the EOG compared with the OG 
at both the $\mathrm{NN}$ and the IT regions in univariate analysis $(\mathrm{p}<0.05)$ (model 1) but this was not significant after adjustments (model 2 and 3). After adjustment with maturation and body mass (model 2), Width, CSMI and Z at the 3 sites were significantly higher in the EOG compared to OG, such as ED at the IT and the FS, and CSA at the FS $(\mathrm{p}<0.05)$. These results were not significant after adjustment with maturation and body fat (model 3). In females, Width, CSMI and $\mathrm{Z}$ at the IT were significantly higher in the EOG compared to OG after adjustment with maturation and body mass $(\mathrm{p}<0.05)$, such as $\mathrm{ED}$ and $\mathrm{Z}$ at the $\mathrm{NN}(\mathrm{p}<0.05)$ (model 2). BMD, ACT and CSA at the NN and the IT were significantly higher in the EOG compared to OG after adjustment with maturation and fat mass percentage $(\mathrm{p}<0.05)($ model 3), which was not the case after adjustments with maturation and body weight (model 2). BR at the IT were significantly lower in the EOG compared to OG after adjustment with maturation and body mass (model 2) and with maturation and fat mass percentage $(\mathrm{p}<0.05)($ model 3).

\subsection{Sex interaction in regard to bone parameters}

P-values for sex interactions are presented in Figure 2. There was no significant sex-interaction for TBLH, lumbar spine, TBS and total hip parameters, neither for HSA parameters.

\subsection{Correlations between anthropometric measurements, body composition and}

\section{bone parameters}

All correlations are presented in Figure 3A for female and Figure 3B for male adolescents. For males, BMI expressed in percentile was significantly positively correlated with LS BMD, hip BMD and BMC, and BMD, ACT and CSA at the 3 hip sites. Correlation tests in both females and males revealed a significant negative correlation between BMI expressed in percentiles and TBS $(\mathrm{p}<0.05)$. FM and FM percentage were significantly inversely correlated with TBS $(\mathrm{p}<0.01)$ only for males. For both sexes, body mass, BMI, LM and FM values were significantly positively correlated with BMC and BMD of whole-body, LS and hip, but also with most of hip bone geometric and mechanical indices, except BR. 


\section{DISCUSSION}

The aim of our study was to determine the impact of the severity of obesity assessed by BMI international classification (obesity versus extreme obesity) on whole-body, lumbar spine, total hip BMD and BMC, and geometric indices of hip bone strength among 12-15 years old adolescents. This is to our knowledge the first study that evaluates the impact of the severity of obesity on extensive bone parameters in a population of adolescents of homogenous age with obesity.

According to our results, the degree of obesity did not impact whole-body BMC and BMD of females and males adolescents. The present results are concordant with the existing literature. In young subjects aged 10-19 years old; while BMD and BMC values were significantly lower from eutrophic to patient with extreme obesity, Mosca et al. also failed to show statistical significance between the group with extreme obesity and the group with obesity when adjusted for chronological age or bone age ${ }^{20}$. In older premenopausal women, Hammoud et al. also found no differences on BMD and BMC values between subjects with severe obesity, morbid obesity and super morbid obesity ${ }^{18}$.

Interestingly, the present results suggest that the severity of obesity can alter lumbar bone density, content and microarchitecture in both sexes. TBS, which is a texture index that evaluates pixel grey level variations and provides an indirect but highly correlated assessment of trabecular microarchitecture between L1-L4 ${ }^{25}$, has been found significantly lower in the group with extreme obesity, independently of the degree of maturation and body mass. Moreover, TBS significantly negatively correlated with BMI expressed in percentile in both sexes, such as with FM and FM percentage in males. To our knowledge, this is the first study to evaluate TBS in regard to the severity of obesity in adolescents. The present results align to the findings of large scale studies examining TBS in men and women across wide age and BMI ranges ${ }^{26,27}$. Our results are also concordant with a more recent study carried out in 
younger premenopausal women and men with overweight and obesity, confirming that TBS was inversely and strongly correlated with BMI, total fat and visceral adipose tissue, independently of $\mathrm{LM}^{28}$. A study conducted among premenopausal females of varying BMI using computed tomography and trans-iliac bone biopsy has shown that at the tissue level, females with more central adiposity had inferior bone quality (in particular lower trabecular bone volume and trabecular stiffness, fewer and thinner trabeculae, and higher cortical porosity) and lower bone formation ${ }^{8}$. This has been explained by the higher sensitivity of trabecular bone, due to its metabolic activity (in comparison to cortical bone), in regard to metabolic impairments ${ }^{8}$. Moreover, Bredella et al reported that premenopausal women with high visceral adipose tissue had higher vertebral bone marrow fat than those with low visceral adipose tissue, and that vertebral bone marrow fat was inversely correlated with vertebral ${ }^{29}$. Thus, the lower TBS associated with the lower lumbar BMD observed in adolescents with extreme obesity in comparison with adolescents with less severe obesity could be partly explained by the higher FM levels (potentially associated with higher visceral adipose tissue and higher bone marrow fat).

Otherwise, for both sexes, the severity of obesity would have a significant positive impact on total hip BMD (independently of body fat percentage), which could be explained by the higher load characterizing adolescents with extreme obesity, who undergo a higher weightbearing locomotion with higher impacts on the hip, inducing a greater osteogenic potential in comparison with adolescents with simple obesity ${ }^{30}$. The severity of obesity also affects several geometric and strength parameters, in particular on BMD, ACT and CSA at both the NN and IT in males. To our knowledge, hip bone geometry and strength had never been explored before in adolescents in regard to the severity of obesity. While CSA is a recognized index of resistance to axial forces, ACT is considered as the HAS femur geometry parameter that is the most negatively associated with the incidence of hip fractures independently of 
$\mathrm{BMD}^{31}$. Moreover, BMI expressed in percentile was significantly positively correlated with hip BMC and BMD, and BMD, ACT and CSA at the three hip sites for males. However, except for females at the IT, the severity of obesity did not seems to impacts BR, which is recognized as an important clinical indicator in regard to the incidence of hip fractures ${ }^{31}$. BR was not correlated with either anthropometrics or body composition variables. The present results remain thus in line with those found in premenopausal women between sever obesity and super morbid obesity groups ${ }^{18}$. Importantly, in regard to the absence of significant interactions between sexes for hip HSA parameters, potential differences between sexes must be interpreted with caution.

The present positive correlation observed in both sexes between weight, BMI, LM and FM values and bone parameters (BMC and BMD of whole-body, LS and hip, but also with most of hip bone geometric and mechanical indices, except BR) are fully in line with the literature, in particular for LM, which is known to have a protective effects on bone mass in adolescents 32,33. Moreover, it has also been shown that LM would be a positive predictor of hip geometry in adults with obesity ${ }^{28}$. Concerning FM, the literature on the relationship between childhood obesity and bone continues to show conflicting results ${ }^{7}$, some studies suggesting a positive relationship between adiposity and bone ${ }^{18,34}$ while others suggesting that excess fat is detrimental to the developing skeleton ${ }^{20,35}$.

The present results have to be considered in light of some limitations. First, the main limitation of this study is that it did not include a group of adolescents with healthy weight, to act as a control group. This would have permit to better translate our results to clinical significance. Secondly, although DXA remains the most common non-invasive technique for assessing pediatric bones ${ }^{36,37}$, it is unable to distinguish trabecular and cortical bone, which respond differently to mechanical loading and metabolic impairments. Indeed, trabecular bone would be more likely altered in subjects with obesity, as more susceptible to metabolic 
impairments in comparison with cortical bone ${ }^{38}$. Also, DXA does not provide a direct distinctive measure of subcutaneous and visceral adipose tissue, which would have an opposite impact on bone ${ }^{7,39}$. Nevertheless, other parameters, such as android, gynoid fat or a proxy of visceral fat measured by DXA would have been interested to assess in this study. Indeed, visceral fat, which was not explored in the present analysis, has been shown associated with higher risk of fracture, through its related inflammation that is responsible for numerous metabolic impairments that would adversely affect bone health ${ }^{8,40}$. Glass et al. described sex differences in the relationship between fat compartments and bone health in 1119 year olds over time ${ }^{41}$. Other methods, such as peripheral quantitative computed tomography (pQCT) would have provided important information on volumetric BMD, bone architecture and quality ${ }^{42}$. Third, we decided to present the results separately for females and males based on the clinical relevance of such an analysis in adolescents and the difference in sample size between sexes, as previously done in the literature ${ }^{20}$. However, as this can be considered as a limitation, the analysis of the sex interactions for each bone variables add informative results for interpretations. Otherwise, while this research study aimed at analysing the impact of the degree of obesity on the skeletal sites involved in fracture risk later in adult life, the choices of whole-body, lumbar spine and hip as regions of interest are relevant and in accordance with official positions from the ISCD ${ }^{22}$. Finally, the study did not explore the impact of clinical and biological metabolic parameters on bone health. Indeed, the higher risk of fracture described in the literature ${ }^{8-11,13}$ could be linked to consequences of obesity, such as inflammation, insulin resistance, type 2 diabetes, dyslipidemia and nonalcoholic fatty liver disease. especially during the adolescent years ${ }^{43-45}$. Future research exploring the impact of clinical and biological markers of metabolic syndrome and complications of obesity on bone health are thus needed. 
In conclusion, the present study, which is the first to evaluate the impact of the severity of obesity on extensive bone parameters in adolescents with obesity, indicates that the degree of obesity might differently affect bone health in adolescents depending on anatomical sites. In both sexes, the severity of obesity might have no significant impact on total body bone mass and density. However, extreme obesity would significantly alters lumbar site and particularly trabecular bone, independently of the degree of maturation and body mass. TBS has been found negatively associated with BMI percentile in both sexes and fat mass in males. Otherwise, extreme obesity might positively impact total hip bone density independently of the degree of maturation and body fat percentage. Future studies should include a group of adolescents with healthy weight and evaluate the impact of the severity of obesity on extensive bone parameters in regard to visceral fat and obesity-related complications including low grade inflammation, parameters of metabolic syndrome like insulin resistance; type 2 diabetes, dyslipidemia and non-alcoholic fatty liver disease. 
1. McGlashan J, Hayward J, Brown A, et al. Comparing complex perspectives on obesity drivers: action-driven communities and evidence-oriented experts. Obes Sci Pract. 2018;4(6):575-581. doi:10.1002/osp4.306

2. Zimmet P, Alberti KGM, Kaufman F, et al. The metabolic syndrome in children and adolescents - an IDF consensus report. Pediatr Diabetes. 2007;8(5):299-306. doi:10.1111/j.13995448.2007.00271.x

3. Tsiros MD, Tian EJ, Shultz SP, et al. Obesity, the new childhood disability? An umbrella review on the association between adiposity and physical function. Obes Rev.

2020;21(12):e13121. doi:https://doi.org/10.1111/obr.13121

4. Daniels SR, Arnett DK, Eckel RH, et al. Overweight in children and adolescents: pathophysiology, consequences, prevention, and treatment. Circulation. 2005;111(15):19992012. doi:10.1161/01.CIR.0000161369.71722.10

5. Shapses SA, Sukumar D. Bone metabolism in obesity and weight loss. Annu Rev Nutr. 2012;32:287-309. doi:10.1146/annurev.nutr.012809.104655

6. Shapses SA, Pop LC, Wang Y. Obesity is a concern for bone health with aging. Nutr Res. 2017;39:1-13. doi:10.1016/j.nutres.2016.12.010

7. Dimitri P. The Impact of Childhood Obesity on Skeletal Health and Development. J Obes Metab Syndr. 2019;28(1):4-17. doi:10.7570/jomes.2019.28.1.4

8. Cohen A, Dempster DW, Recker RR, et al. Abdominal Fat Is Associated With Lower Bone Formation and Inferior Bone Quality in Healthy Premenopausal Women: A Transiliac Bone Biopsy Study. J Clin Endocrinol Metab. 2013;98(6):2562-2572. doi:10.1210/jc.2013-1047

9. Dimitri P, Bishop N, Walsh JS, Eastell R. Obesity is a risk factor for fracture in children but is protective against fracture in adults: a paradox. Bone. 2012;50(2):457-466.

doi:10.1016/j.bone.2011.05.011

10. Goulding A, Grant AM, Williams SM. Bone and body composition of children and adolescents with repeated forearm fractures. J Bone Miner Res Off J Am Soc Bone Miner Res. 2005;20(12):2090-2096. doi:10.1359/JBMR.050820

11. Goulding A, Taylor RW, Jones IE, McAuley KA, Manning PJ, Williams SM. Overweight and obese children have low bone mass and area for their weight. Int J Obes Relat Metab Disord J Int Assoc Study Obes. 2000;24(5):627-632. doi:10.1038/sj.ijo.0801207

12. Chaplais E, Naughton G, Dutheil F, et al. Geometric and Mechanical Bone Response to a Multidisciplinary Weight Loss Intervention in Adolescents With Obesity: The ADIBOX Study. J Clin Densitom Off J Int Soc Clin Densitom. June 2018. doi:10.1016/j.jocd.2018.06.002

13. Fintini D, Cianfarani S, Cofini M, et al. The Bones of Children With Obesity. Front Endocrinol. 2020;11:200. doi:10.3389/fendo.2020.00200

14. Gómez-Ambrosi J, Rodríguez A, Catalán V, Frühbeck G. The Bone-Adipose Axis in Obesity and Weight Loss. Obes Surg. 2008;18(9):1134-1143. doi:10.1007/s11695-008-9548-1 
15. Elmesmari R, Martin A, Reilly JJ, Paton JY. Comparison of accelerometer measured levels of physical activity and sedentary time between obese and non-obese children and adolescents: a systematic review. BMC Pediatr. 2018;18. doi:10.1186/s12887-018-1031-0

16. Saggese G, Vierucci F, Boot AM, et al. Vitamin D in childhood and adolescence: an expert position statement. Eur J Pediatr. 2015;174(5):565-576. doi:10.1007/s00431-015-2524-6

17. Gómez JM, Vilarrasa N, Masdevall C, et al. Regulation of Bone Mineral Density in Morbidly Obese Women: A Cross-sectional Study in Two Cohorts Before and After Bypass Surgery. Obes Surg. 2009;19(3):345-350. doi:10.1007/s11695-008-9529-4

18. Hammoud E, Toumi H, Jacob C, Pinti A, Lespessailles E, El Hage R. Does the Severity of Obesity Influence Bone Mineral Density Values in Premenopausal Women? J Clin Densitom Off J Int Soc Clin Densitom. April 2019. doi:10.1016/j.jocd.2019.04.006

19. Rocher E, Chappard C, Jaffre C, Benhamou C-L, Courteix D. Bone mineral density in prepubertal obese and control children: relation to body weight, lean mass, and fat mass. $J$ Bone Miner Metab. 2008;26(1):73-78. doi:10.1007/s00774-007-0786-4

20. Mosca LN, Goldberg TBL, da Silva VN, et al. Excess body fat negatively affects bone mass in adolescents. Nutrition. 2014;30(7-8):847-852. doi:10.1016/j.nut.2013.12.003

21. Freedman DS, Katzmarzyk PT, Dietz WH, Srinivasan SR, Berenson GS. Relation of body mass index and skinfold thicknesses to cardiovascular disease risk factors in children: the Bogalusa Heart Study. Am J Clin Nutr. 2009;90(1):210-216. doi:10.3945/ajen.2009.27525

22. Crabtree NJ, Arabi A, Bachrach LK, et al. Dual-Energy X-Ray Absorptiometry Interpretation and Reporting in Children and Adolescents: The Revised 2013 ISCD Pediatric Official Positions. J Clin Densitom. 2014;17(2):225-242. doi:10.1016/j.jocd.2014.01.003

23. Kalkwarf HJ, Zemel BS, Gilsanz V, et al. The bone mineral density in childhood study: bone mineral content and density according to age, sex, and race. J Clin Endocrinol Metab. 2007;92(6):2087-2099. doi:10.1210/jc.2006-2553

24. Beck TJ. Extending DXA beyond bone mineral density: understanding hip structure analysis. Curr Osteoporos Rep. 2007;5(2):49-55. doi:10.1007/s11914-007-0002-4

25. Bazzocchi A, Ponti F, Diano D, et al. Trabecular bone score in healthy ageing. Br J Radiol. 2015;88(1052):20140865. doi:10.1259/bjr.20140865

26. Sritara C, Thakkinstian A, Ongphiphadhanakul B, et al. Age-Adjusted Dual X-ray Absorptiometry-Derived Trabecular Bone Score Curve for the Lumbar Spine in Thai Females and Males. J Clin Densitom Off J Int Soc Clin Densitom. 2016;19(4):494-501. doi:10.1016/j.jocd.2015.05.068

27. Leslie WD, Krieg M-A, Hans D, Manitoba Bone Density Program. Clinical factors associated with trabecular bone score. J Clin Densitom Off J Int Soc Clin Densitom. 2013;16(3):374-379. doi:10.1016/j.jocd.2013.01.006

28. Schorr M, Dichtel LE, Gerweck AV, Torriani M, Miller KK, Bredella MA. Body composition predictors of skeletal integrity in obesity. Skeletal Radiol. 2016;45(6):813-819. doi:10.1007/s00256-016-2363-1 
29. Bredella MA, Torriani M, Ghomi RH, et al. Vertebral bone marrow fat is positively associated with visceral fat and inversely associated with IGF-1 in obese women. Obes Silver Spring Md. 2011;19(1):49-53. doi:10.1038/oby.2010.106

30. Turner CH. Three rules for bone adaptation to mechanical stimuli. Bone. 1998;23(5):399-407. doi:10.1016/s8756-3282(98)00118-5

31. Kaptoge S, Beck TJ, Reeve J, et al. Prediction of incident hip fracture risk by femur geometry variables measured by hip structural analysis in the study of osteoporotic fractures. J Bone Miner Res Off J Am Soc Bone Miner Res. 2008;23(12):1892-1904. doi:10.1359/jbmr.080802

32. Sioen I, Lust E, De Henauw S, Moreno LA, Jiménez-Pavón D. Associations Between Body Composition and Bone Health in Children and Adolescents: A Systematic Review. Calcif Tissue Int. 2016;99(6):557-577. doi:10.1007/s00223-016-0183-x

33. El Hage R, Jacob C, Moussa E, et al. Influence of the weight status on bone mineral content and bone mineral density in a group of Lebanese adolescent girls. Joint Bone Spine. 2009;76(6):680684. doi:10.1016/j.jbspin.2009.10.004

34. Mosca LN, Goldberg TBL, da Silva VN, et al. The impact of excess body fat on bone remodeling in adolescents. Osteoporos Int J Establ Result Coop Eur Found Osteoporos Natl Osteoporos Found USA. 2017;28(3):1053-1062. doi:10.1007/s00198-016-3838-6

35. Farr JN, Chen Z, Lisse JR, Lohman TG, Going SB. Relationship of total body fat mass to weight-bearing bone volumetric density, geometry, and strength in young girls. Bone. 2010;46(4):977-984. doi:10.1016/j.bone.2009.12.033

36. Ivuskans A, Lätt E, Mäestu J, et al. Bone mineral density in 11-13-year-old boys: relative importance of the weight status and body composition factors. Rheumatol Int. 2013;33(7):16811687. doi:10.1007/s00296-012-2612-0

37. Guss CE, McAllister A, Gordon CM. DXA in Children and Adolescents. J Clin Densitom Off J Int Soc Clin Densitom. January 2020. doi:10.1016/j.jocd.2020.01.006

38. Boot AM, Engels MA, Boerma GJ, Krenning EP, De Muinck Keizer-Schrama SM. Changes in bone mineral density, body composition, and lipid metabolism during growth hormone (GH) treatment in children with GH deficiency. J Clin Endocrinol Metab. 1997;82(8):2423-2428. doi:10.1210/jcem.82.8.4149

39. Pollock NK, Laing EM, Baile CA, Hamrick MW, Hall DB, Lewis RD. Is adiposity advantageous for bone strength? A peripheral quantitative computed tomography study in late adolescent females. Am J Clin Nutr. 2007;86(5):1530-1538. doi:10.1093/ajcn/86.5.1530

40. Sadeghi O, Saneei P, Nasiri M, Larijani B, Esmaillzadeh A. Abdominal Obesity and Risk of Hip Fracture: A Systematic Review and Meta-Analysis of Prospective Studies. Adv Nutr Bethesda Md. 2017;8(5):728-738. doi:10.3945/an.117.015545

41. Glass NA, Torner JC, Letuchy EM, et al. Does Visceral or Subcutaneous Fat Influence Peripheral Cortical Bone Strength During Adolescence? A Longitudinal Study. J Bone Miner Res Off J Am Soc Bone Miner Res. 2018;33(4):580-588. doi:10.1002/jbmr.3325

42. Specker BL, Schoenau E. Quantitative Bone Analysis in Children: Current Methods and Recommendations. J Pediatr. 2005;146(6):726-731. doi:10.1016/j.jpeds.2005.02.002 
43. Kelley JC, Crabtree N, Zemel BS. Bone Density in the Obese Child: Clinical Considerations and Diagnostic Challenges. Calcif Tissue Int. 2017;100(5):514-527. doi:10.1007/s00223-0160233-4

44. Gower BA, Casazza K. Divergent Effects of Obesity on Bone Health. J Clin Densitom. 2013;16(4):450-454. doi:10.1016/j.jocd.2013.08.010

45. da Silva VN, Fiorelli LNM, da Silva CC, Kurokawa CS, Goldberg TBL. Do metabolic syndrome and its components have an impact on bone mineral density in adolescents? Nutr Metab. 2017;14. doi:10.1186/s12986-016-0156-0 
Figure 1: Hip image from a Hologic DXA scanner showing positions of thin analysis regions across the femur at the neck (NN), intertrochanteric (IT) and shaft (FS) using the Hip Structural Analysis (HAS). On the left are shown typical bone mass profiles used in measurements of geometric and strength properties. Adapted from Beck et al ${ }^{24}$

\section{Figure 2: Sex interaction (p-value) for bone parameters}

ACT: average cortical thickness; BMC: bone mineral content; BMD: Bone mineral density; BR: buckling ratio; CSA: cross sectional area; CSMI: cross sectional moment of inertia; ED: endocortical diameter; FS: femoral shaft; IT: intertrochanteric region; LS: lumbar spine; NN: narrow neck; TBLH: Total body less head; TBS: trabecular bone score; Z: section modulus

Figure 3: Heatmap representation of the correlations between anthropometric measurements, body composition and bone variables. The darkest is the box and the higher is the correlation. ACT: average cortical thickness; BMC: bone mineral content; BMD: Bone mineral density; BMI: Body mass index; BR: buckling ratio; CSA: cross sectional area; CSMI: cross sectional moment of inertia; ED: endocortical diameter; FM: fat mass; FS: femoral shaft; IT: intertrochanteric region; LM: lean mass; LS: lumbar spine; NN: narrow neck; TBLH: Total body less head; TBS: trabecular bone score; WB: Whole-body; Z: section modulus; *p $<0.05$ ;**p $<0.01 ; * * * \mathrm{p}<0.001$

Table 1: Anthropometric measurements, body composition and bone parameters of female adolescents for the two groups (obesity vs extreme obesity) $(n=97$; mean \pm SD)

Table 2: Anthropometric measurements, body composition and bone parameters of male adolescents for the two groups (obesity vs extreme obesity) $(n=59$; mean \pm SD) 

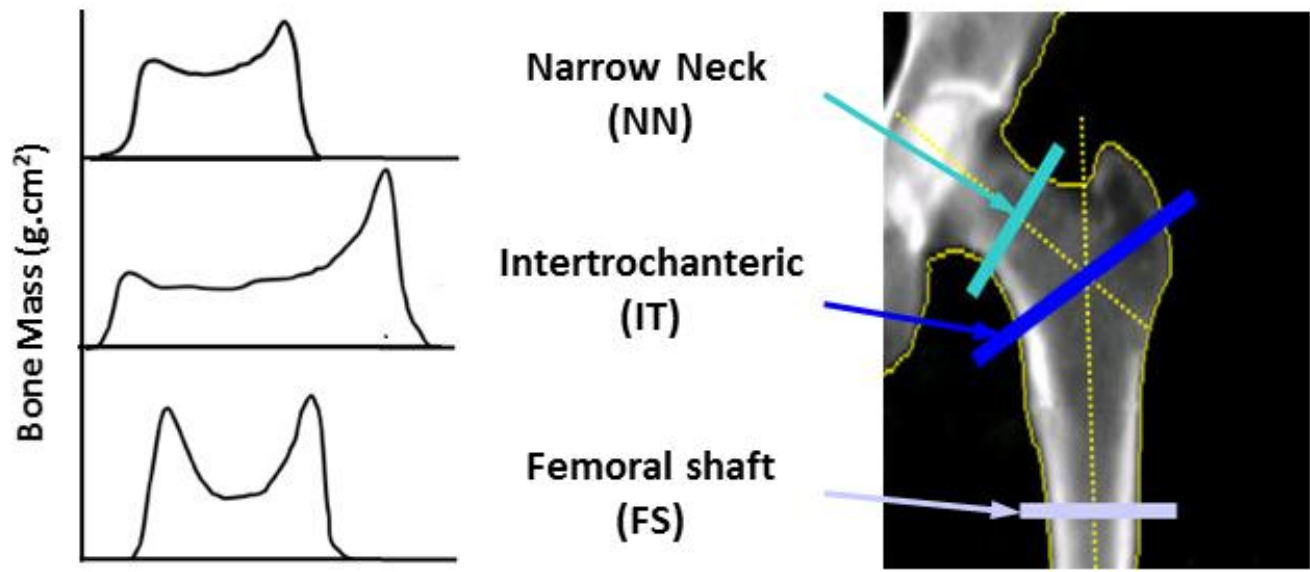

Figure 1 


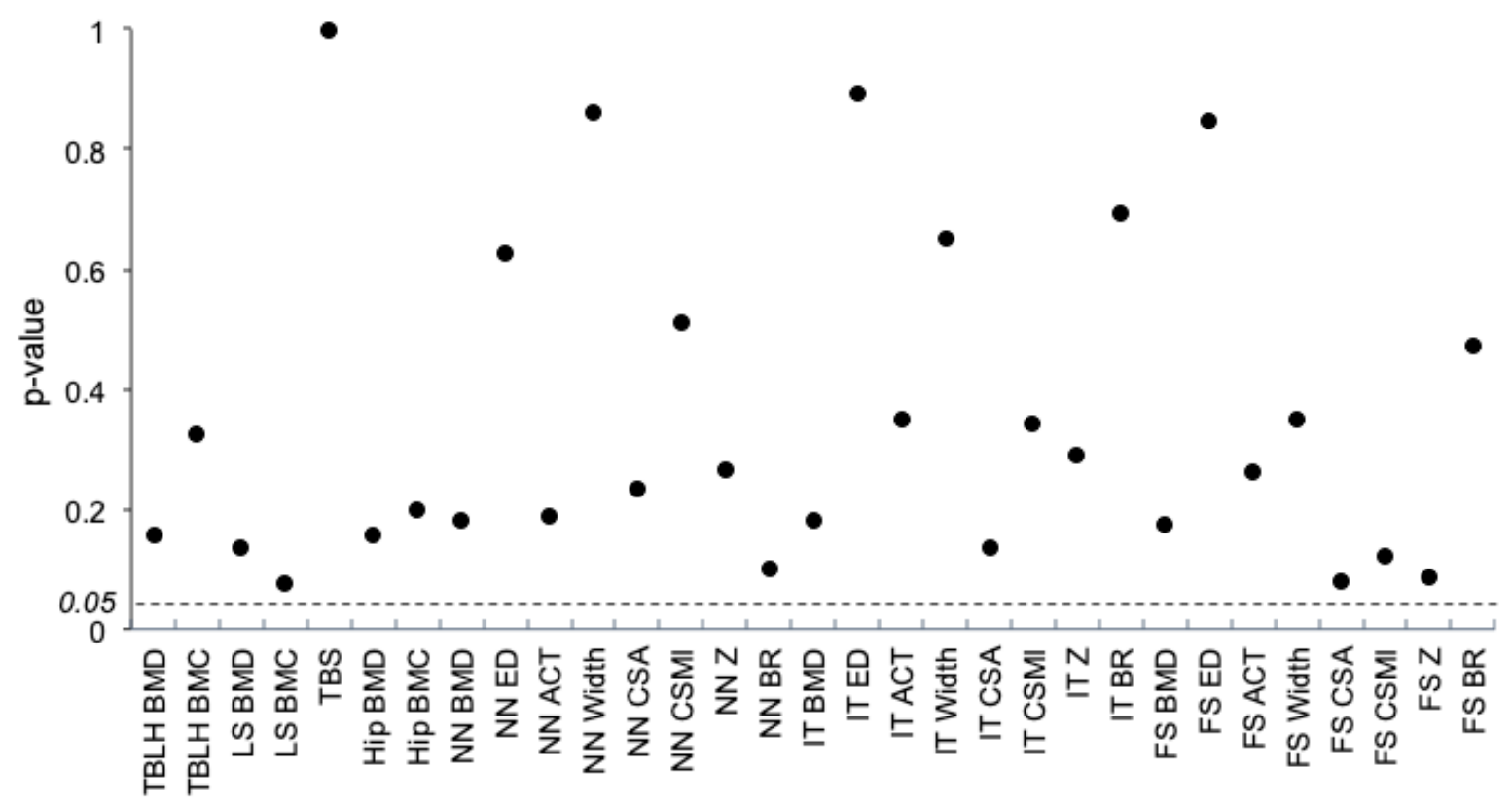

Figure 2 


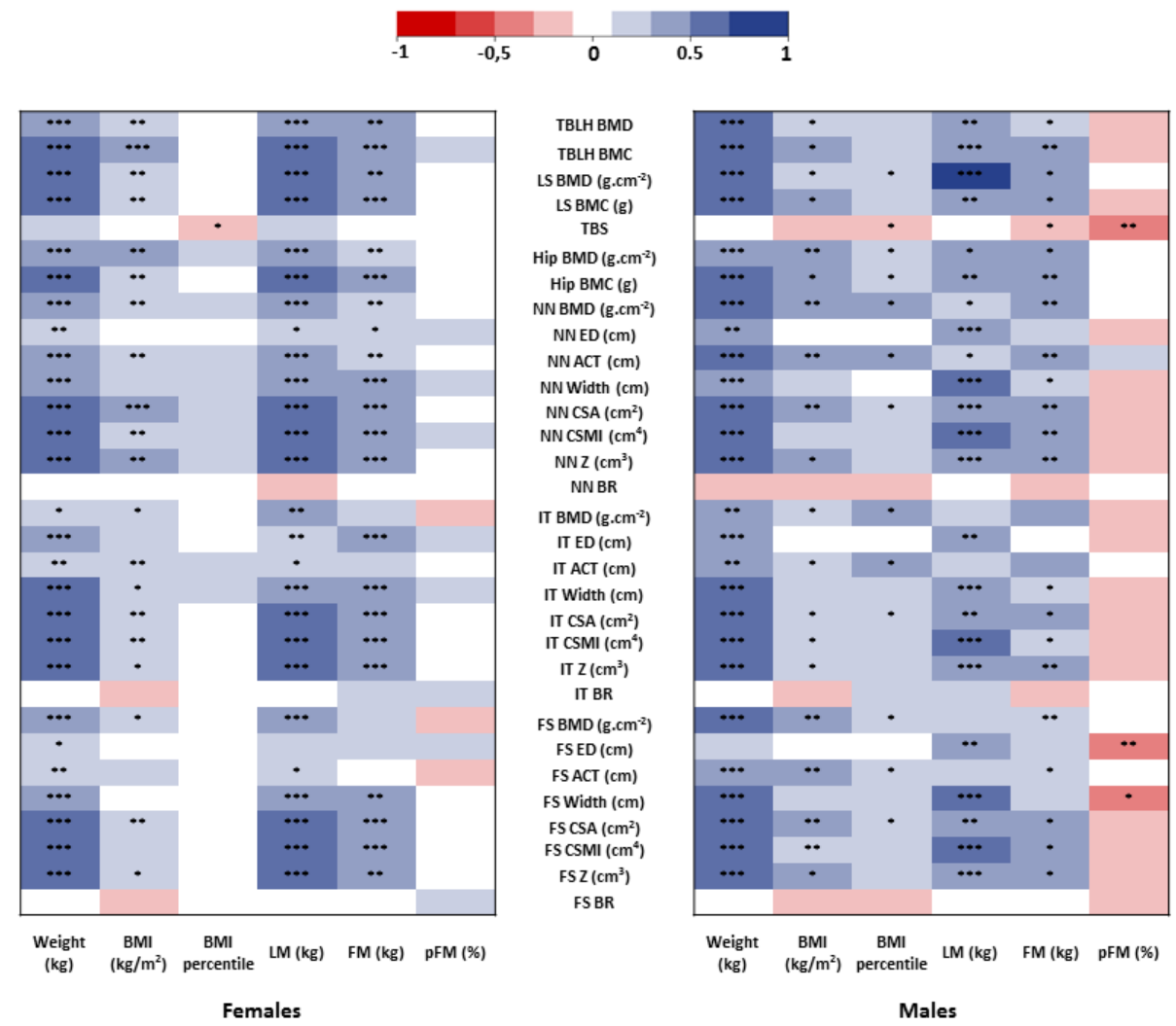

Figure 3 
Table 1:

\begin{tabular}{|c|c|c|c|c|c|c|c|c|c|c|c|}
\hline & $\begin{array}{l}\text { Overall } \\
(n=134)\end{array}$ & $\begin{array}{l}\text { SED- } \\
(n=67)\end{array}$ & $\begin{array}{c}\text { SED+ } \\
(n=67)\end{array}$ & $\begin{array}{l}\text { p-value } \\
\text { Model } 1\end{array}$ & $\begin{array}{l}\text { p-value } \\
\text { Model } 2\end{array}$ & $\begin{array}{l}\text { p-value } \\
\text { Model } 3\end{array}$ & $\begin{array}{c}\text { MVPA+ } \\
(n=67)\end{array}$ & $\begin{array}{l}\text { MVPA- } \\
(n=67)\end{array}$ & $\begin{array}{l}\text { p-value } \\
\text { Model } 1\end{array}$ & $\begin{array}{l}\text { p-value } \\
\text { Model } 2\end{array}$ & $\begin{array}{l}\text { p-value } \\
\text { Model } 3\end{array}$ \\
\hline \multicolumn{12}{|l|}{ Anthropometry - body composition } \\
\hline Age (year) & $13.4 \pm 2.2$ & $13.1 \pm 2.3$ & $13.6 \pm 1.9$ & 0.093 & & & $13.0 \pm 2.3$ & $13.7 \pm 1.9$ & 0.024 & & \\
\hline Females (n, \%) & $65(48.5)$ & $33(49)$ & $32(47)$ & 0.863 & & & $33(49)$ & $32(47)$ & 0.863 & & \\
\hline Tanner stage & $3.8 \pm 1.3$ & $3.7 \pm 1.3$ & $3.9 \pm 1.3$ & 0.549 & & & $3.7 \pm 1.3$ & $3.9 \pm 1.3$ & 0.747 & & \\
\hline Height $(\mathrm{cm})$ & $164.1 \pm 13.6$ & $161.2 \pm 16.2$ & $167.1 \pm 9.7$ & 0.013 & & & $159.3 \pm 14.8$ & $168.8 \pm 10.4$ & $<0.001$ & & \\
\hline Weight (kg) & $93.2 \pm 25.1$ & $87.6 \pm 28.8$ & $98.9 \pm 19.5$ & 0.004 & 0.009 & & $83.8 \pm 25.2$ & $102.7 \pm 21.3$ & $<0.001$ & $<0.001$ & \\
\hline $\mathrm{BMI}\left(\mathrm{kg} \cdot \mathrm{m}^{-2}\right)$ & $34.3 \pm 5.2$ & $32.9 \pm 5.5$ & $35.6 \pm 4.5$ & 0.002 & 0.017 & & $32.6 \pm 4.8$ & $36.1 \pm 5.0$ & $<0.001$ & 0.006 & \\
\hline Z-BMI & $3.18 \pm 0.48$ & $3.19 \pm 0.51$ & $3.26 \pm 0.45$ & 0.042 & 0.161 & & $3.14 \pm 0.48$ & $3.22 \pm 0.48$ & 0.041 & 0.189 & \\
\hline BMI (percentile) & $98.9 \pm 0.7$ & $98.8 \pm 0.8$ & $99.0 \pm 0.7$ & 0.015 & 0.014 & & $98.8 \pm 0.8$ & $99.0 \pm 0.7$ & 0.011 & 0.014 & \\
\hline WC $(\mathrm{cm})$ & $109.0 \pm 13.8$ & $105.8 \pm 15.1$ & $112.3 \pm 11.5$ & 0.012 & 0.024 & 0.155 & $103.7 \pm 13.8$ & $114.3 \pm 11.7$ & $<0,001$ & 0,001 & 0,109 \\
\hline $\mathrm{HC}(\mathrm{cm})$ & $11.7 \pm 13.4$ & $108.1 \pm 14.7$ & $115.7 \pm 10.5$ & 0.001 & 0.024 & 0.171 & $106.5 \pm 13.7$ & $117.1 \pm 10.7$ & $<0.001$ & 0.001 & 0.056 \\
\hline Waist to hip ratio & $0.98 \pm 0.07$ & $0.98 \pm 0.08$ & $0.98 \pm 0.07$ & 0.458 & 0.554 & 0.386 & $0.98 \pm 0.08$ & $0.98 \pm 0.06$ & 0.552 & 0.657 & 0.961 \\
\hline $\mathrm{FM}(\mathrm{kg})$ & $41.2 \pm 14.4$ & $36.4 \pm 14.9$ & $46.0 \pm 12$ & $<0.001$ & 0.031 & 0.118 & $35.0 \pm 13.6$ & $47.7 \pm 12.2$ & $<0.001$ & 0.001 & 0.136 \\
\hline FM percentage (\%) & $44.0 \pm 7.3$ & $41.9 \pm 6.5$ & $46.1 \pm 7.6$ & 0.002 & 0.011 & 0.036 & $42.3 \pm 7.0$ & $45.7 \pm 7.3$ & 0.015 & 0.017 & 0.124 \\
\hline $\mathrm{FFM}(\mathrm{kg})$ & $51.8 \pm 15.4$ & $49.5 \pm 17.1$ & $54.0 \pm 13.1$ & 0.115 & 0.184 & 0.158 & $47.0 \pm 15.6$ & $56.8 \pm 13.4$ & $<0.001$ & 0.025 & 0.257 \\
\hline FFM percentage (\%) & $56.0 \pm 7.0$ & $58.1 \pm 6.8$ & $53.9 \pm 7.2$ & 0.005 & 0.011 & 0.037 & $57.7 \pm 6.8$ & $54.3 \pm 7.2$ & 0.024 & 0.025 & 0.126 \\
\hline $\operatorname{VAT}\left(\mathrm{cm}^{3}\right)$ & $1699 \pm 565$ & $1517 \pm 572$ & $1867 \pm 480$ & 0.015 & 0.065 & 0.088 & $1555 \pm 599$ & $1832 \pm 508$ & 0.043 & 0.418 & 0.684 \\
\hline $\operatorname{SAT}\left(\mathrm{cm}^{3}\right)$ & $7722 \pm 1939$ & $7000 \pm 2175$ & $8320 \pm 1416$ & 0.012 & 0.026 & 0.035 & $7338 \pm 2397$ & $8077 \pm 1347$ & 0.139 & 0.578 & 0.826 \\
\hline \multicolumn{12}{|l|}{ Movement related behaviors } \\
\hline Accelerometer days worn (n) & $6.5 \pm 1.1$ & $6.6 \pm 0.8$ & $6.3 \pm 1.1$ & 0.203 & 0.512 & 0.866 & $6.6 \pm 0.8$ & $6.3 \pm 1.1$ & 0.081 & 0.100 & 0.313 \\
\hline Accelerometer daily wear time (\%) & $99.4 \pm 2.9$ & $99.3 \pm 2.7$ & $99.5 \pm 3.1$ & 0.761 & 0.666 & 0.850 & $99.4 \pm 2.5$ & $99.3 \pm 3.3$ & 0.888 & 0.900 & 0.820 \\
\hline Sedentary time (min/day) & $640 \pm 116$ & $557 \pm 38$ & $723 \pm 109$ & $<0.001$ & $<0.001$ & $<0.001$ & $584 \pm 61$ & $696 \pm 171$ & $<0.001$ & $<0.001$ & $<0.001$ \\
\hline LPA (min/day) & $484 \pm 107$ & $533 \pm 88$ & $433 \pm 103$ & $<0.001$ & $<0.001$ & $<0.001$ & $494 \pm 80$ & $473 \pm 111$ & 0.401 & 0.276 & 0.322 \\
\hline MPA (min/day) & $186 \pm 76$ & $222 \pm 75$ & $149 \pm 59$ & $<0.001$ & $<0.001$ & $<0.001$ & $248 \pm 50$ & $124 \pm 84$ & 0.001 & $<0.001$ & $<0.001$ \\
\hline VPA (min/day) & $6 \pm 10$ & $8 \pm 14$ & $4 \pm 5$ & 0.023 & 0.047 & 0.145 & $10 \pm 13$ & $2 \pm 3$ & $<0.001$ & $<0.001$ & $<0.001$ \\
\hline MVPA (min/day) & $192 \pm 81$ & $231 \pm 81$ & $153 \pm 61$ & $<0.001$ & $<0.001$ & $<0.001$ & $258 \pm 56$ & $127 \pm 86$ & $<0.001$ & $<0.001$ & $<0.001$ \\
\hline Total PA (min/day) & $676 \pm 139$ & $764 \pm 72$ & $586 \pm 135$ & $<0.001$ & $<0.001$ & $<0.001$ & $752 \pm 81$ & $599 \pm 144$ & $<0.001$ & $<0.001$ & $<0.001$ \\
\hline
\end{tabular}




\begin{tabular}{|c|c|c|c|c|c|c|c|c|c|c|c|}
\hline MVPA/LPA ratio & $0.42 \pm 0.22$ & $0.47 \pm 0.25$ & $0.37 \pm 0.17$ & 0.011 & 0.113 & 0.216 & $0.55 \pm 0.21$ & $0.29 \pm 0.13$ & $<0.001$ & $<0.001$ & $<0.001$ \\
\hline AEE & $2345 \pm 1130$ & $2387 \pm 1172$ & $2299 \pm 1102$ & 0.494 & 0.249 & 0.114 & $2383 \pm 899$ & $2304 \pm 1327$ & 0.117 & 0.207 & 0.059 \\
\hline Self-reported sports time (h/week) (a) & $6.67 \pm 3.6$ & $7.52 \pm 3.1$ & $5.80 \pm 3.8$ & 0.013 & 0.020 & 0.022 & $7.76 \pm 3.5$ & $5.68 \pm 3.5$ & 0.006 & 0.012 & 0.013 \\
\hline \multicolumn{12}{|l|}{ Cardiometabolic variables } \\
\hline Systolic BP (mmHg) & $119 \pm 12$ & $116 \pm 12$ & $122 \pm 11$ & 0.001 & 0.021 & 0.048 & $116 \pm 11$ & $122 \pm 11$ & $<0.001$ & 0.033 & 0.090 \\
\hline Diastolic BP (mmHg) & $72 \pm 9$ & $70 \pm 9$ & $74 \pm 8$ & 0.012 & 0.039 & 0.022 & $70 \pm 8$ & $73 \pm 9$ & 0.018 & 0.183 & 0.097 \\
\hline HDL-cholesterol (mmol/L) & $1.06 \pm 0.23$ & $1.16 \pm 0.24$ & $0.96 \pm 0.20$ & $<0.001$ & 0.001 & 0.001 & $1.14 \pm 0.25$ & $0.98 \pm 0.21$ & $<0.001$ & 0.008 & 0.013 \\
\hline Triglycerides (mmol/L) & $1.22 \pm 0.58$ & $1.09 \pm 0.56$ & $1.36 \pm 0.58$ & 0.003 & 0.049 & 0.061 & $1.07 \pm 0.53$ & $1.38 \pm 0.60$ & $<0.001$ & 0.027 & 0.026 \\
\hline LDL-cholesterol (mmol/L) & $2.61 \pm 0.81$ & $2.50 \pm 0.71$ & $2.71 \pm 0.89$ & 0.149 & 0.071 & 0.055 & $2.51 \pm 0.77$ & $2.70 \pm 0.84$ & 0.160 & 0.144 & 0.102 \\
\hline Total cholesterol $(\mathrm{mmol} / \mathrm{L})$ & $3.92 \pm 0.90$ & $3.88 \pm 0.83$ & $3.96 \pm 0.96$ & 0.501 & 0.170 & 0.112 & $3.87 \pm 0.87$ & $3.96 \pm 0.92$ & 0.626 & 0.509 & 0.338 \\
\hline Apolipoproteine A ( $(\mathrm{L} / \mathrm{L})$ & $1.28 \pm 0.18$ & $1.32 \pm 0.21$ & $1.24 \pm 0.13$ & 0.008 & 0.033 & 0.063 & $1.33 \pm 0.21$ & $1.24 \pm 0.13$ & 0.004 & 0.017 & 0.065 \\
\hline Apolipoproteine B (g/L) & $0.76 \pm 0.20$ & $0.70 \pm 0.17$ & $0.80 \pm 0.22$ & 0.005 & 0.007 & 0.007 & $0.72 \pm 0.19$ & $0.79 \pm 0.21$ & 0.023 & 0.102 & 0.117 \\
\hline HsCRP (mg/L) & $2.01 \pm 2.10$ & $1.59 \pm 1.54$ & $2.41 \pm 2.47$ & 0.214 & 0.140 & 0.219 & $1.80 \pm 1.30$ & $2.19 \pm 2.61$ & 0.380 & 0.799 & 0.670 \\
\hline Fasting glucose (mmol/L) & $5.55 \pm 0.59$ & $5.39 \pm 0.49$ & $5.72 \pm 0.64$ & 0.002 & 0.001 & 0.001 & $5.51 \pm 0.60$ & $5.59 \pm 0.59$ & 0.358 & 0.243 & 0.275 \\
\hline Fasting insulin (mUl/L) & $24.12 \pm 14.25$ & $19.24 \pm 11.41$ & $28.93 \pm 15.19$ & $<0.001$ & $<0.001$ & $<0.001$ & $20.15 \pm 13.18$ & $28.03 \pm 14.29$ & $<0.001$ & 0.003 & 0.005 \\
\hline HOMA-IR & $6.02 \pm 3.91$ & $4.57 \pm 2.94$ & $7.46 \pm 4.23$ & $<0.001$ & $<0.001$ & $<0.001$ & $4.97 \pm 3.74$ & $7.06 \pm 3.82$ & $<0.001$ & 0.002 & 0.003 \\
\hline OGTT glucose $(\mathrm{mmol} / \mathrm{L})$ & $7.04 \pm 1.55$ & $6.73 \pm 1.11$ & $7.37 \pm 1.85$ & 0.020 & 0.041 & 0.043 & $6.85 \pm 1.72$ & $7.24 \pm 1.34$ & 0.051 & 0.259 & 0.147 \\
\hline OGTT Insulin (mUI/L) & $88.6 \pm 73.2$ & $67.6 \pm 51.7$ & $109.6 \pm 85.1$ & 0.008 & 0.033 & 0.023 & $75.6 \pm 58.5$ & $102.0 \pm 84.3$ & 0.127 & 0.420 & 0.315 \\
\hline Metscore (Z-score) & $0.00 \pm 0.62$ & $-0.31 \pm 0.54$ & $0.32 \pm 0.53$ & $<0.001$ & $<0.001$ & $<0.001$ & $-0.28 \pm 0.61$ & $0.29 \pm 0.48$ & $<0.001$ & $<0.001$ & $<0.001$ \\
\hline
\end{tabular}

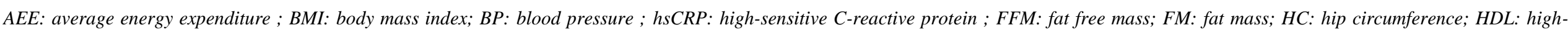

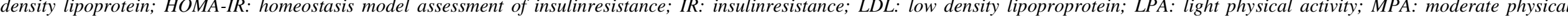

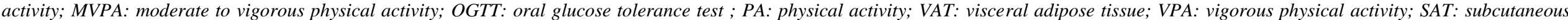
adipose tissue; WC: waist circumference

(a) Self-reported sports time ( $h /$ week) (b): overall: $n=108 ;$; SED-: $n=54 ; S E D+: n=54 ; M V P A+: n=56 ; M V P A-: n=52$ 
Table 2:

\begin{tabular}{|c|c|c|c|c|c|}
\hline & $\begin{array}{c}\text { SED- / MVPA+ } \\
\qquad(n=33)\end{array}$ & $\begin{array}{c}\text { SED- / MVPA- } \\
\qquad(n=34)\end{array}$ & $\begin{array}{c}\text { SED+ / MVPA+ } \\
\quad(n=33)\end{array}$ & $\begin{array}{c}\text { SED+ / MVPA- } \\
\quad(n=34)\end{array}$ & p-value \\
\hline \multicolumn{6}{|l|}{ Anthropometry and body composition } \\
\hline Age (year) & $12.4 \pm 2.3$ & $13.6 \pm 2.2$ & $13.1 \pm 1.8$ & $14.2 \pm 1.9$ & \\
\hline Females (n, \%) & $15(45)$ & $17(50)$ & $16(48)$ & $18(52)$ & \\
\hline Tanner stage & $3.4 \pm 1.5$ & $3.9 \pm 1.3$ & $3.7 \pm 1.3$ & $4.1 \pm 1.2$ & \\
\hline Height (cm) & $152.6 \pm 14.4$ & $169.4 \pm 13.5$ & $165.2 \pm 9.3$ & $168.8 \pm 9.9$ & \\
\hline Weight (kg) & $74.3 \pm 22.4$ & $100.6 \pm 28.8 * *$ & $94.9 \pm 20.4 * *$ & $102.9 \pm 17.8 * *$ & $<0.001$ \\
\hline $\mathrm{BMI}\left(\mathrm{kg} \cdot \mathrm{m}^{-2}\right)$ & $31.3 \pm 4.6$ & $34.6 \pm 5.9$ & $35.3 \pm 4.8$ & $36.0 \pm 4.3 *$ & 0.001 \\
\hline Z-BMI & $3.24 \pm 0.54$ & $3.14 \pm 0.48$ & $3.18 \pm 0.48$ & $3.17 \pm 0.43$ & 0.229 \\
\hline BMI (percentile) & $98.7 \pm 0.8$ & $98.8 \pm 0.8$ & $98.9 \pm 0.7$ & $99.1 \pm 0.6$ & 0.181 \\
\hline WC $(\mathrm{cm})$ & $99.9 \pm 11.9$ & $111.6 \pm 15.9$ & $110.9 \pm 12.3$ & $113.6 \pm 10.8 *$ & $<0.001$ \\
\hline $\mathrm{HC}(\mathrm{cm})$ & $101.4 \pm 12.6$ & $114.6 \pm 13.8 *$ & $113.1 \pm 11.3 *$ & $117.9 \pm 9.5 *$ & $<0.001$ \\
\hline Waist to hip ratio & $0.99 \pm 0.07$ & $0.98 \pm 0.09$ & $0.98 \pm 0.06$ & $0.96 \pm 0.07$ & 0.293 \\
\hline $\mathrm{FM}(\mathrm{kg})$ & $30.6 \pm 10.9$ & $42.7 \pm 16.2$ & $44.4 \pm 13.4 *$ & $47.4 \pm 10.9 * *$ & $<0.001$ \\
\hline FM percentage (\%) & $41.9 \pm 6.6$ & $42.0 \pm 6.5$ & $46.0 \pm 6.9 * \#$ & $46.1 \pm 7.5 * \#$ & 0.029 \\
\hline $\mathrm{FFM}(\mathrm{kg})$ & $42.1 \pm 14.9$ & $57.4 \pm 15.9 *$ & $51.1 \pm 13.0 *$ & $56.4 \pm 12.7^{*}$ & $<0.001$ \\
\hline FFM percentage (\%) & $58.1 \pm 7.0$ & $58.0 \pm 6.7$ & $54.0 \pm 6.4 * \#$ & $53.9 \pm 7.1 * \#$ & 0.023 \\
\hline $\operatorname{VAT}\left(\mathrm{cm}^{3}\right)$ & $1378 \pm 566$ & $1617 \pm 576$ & $1851 \pm 641 *$ & $1884 \pm 404 *$ & 0.047 \\
\hline $\operatorname{SAT}\left(\mathrm{cm}^{3}\right)$ & $6126 \pm 2256$ & $7624 \pm 1960$ & $8224 \pm 1606 *$ & $8558 \pm 1282 *$ & 0.013 \\
\hline \multicolumn{6}{|l|}{ Movement related behaviors } \\
\hline Number of days worn $(n)$ & $6.7 \pm 0.7$ & $6.5 \pm 0.9$ & $6.6 \pm 0.9$ & $6.5 \pm 1.4$ & 0.143 \\
\hline Daily wear time (\%) & $99.3 \pm 3.5$ & $99.4 \pm 2.0$ & $99.7 \pm 1.1$ & $99.3 \pm 2.3$ & 0.946 \\
\hline Sedentary time (min/day) & $553 \pm 44$ & $562 \pm 31$ & $674 \pm 50 * * * \# \#$ & $769 \pm 129 * * * \# \#^{\dagger+\dagger}$ & $<0.001$ \\
\hline Light PA (min/day) & $496 \pm 82$ & $570 \pm 78$ & $460 \pm 59 \# \#$ & $408 \pm 127 * * \# \#^{\dagger}$ & $<0.001$ \\
\hline Moderate PA (min/day) & $281 \pm 46$ & $165 \pm 49 * * *$ & $197 \pm 37 * * * \# \#$ & $104 \pm 35 * * * \# \# \#^{\dagger+\dagger}$ & $<0.001$ \\
\hline Vigorous PA (min/day) & $13 \pm 18$ & $4 \pm 5 * *$ & $6 \pm 5$ & $2 \pm 2 * * *^{t+\dagger}$ & $<0.001$ \\
\hline MVPA (min/day) & $294 \pm 53$ & $169 \pm 51 * * *$ & $203 \pm 38 * * * \# \#$ & $106 \pm 36 * * * \# \#^{\dagger+\dagger}$ & $<0.001$ \\
\hline Total PA (min/day) & $790 \pm 65$ & $739 \pm 71$ & $663 \pm 68 *$ & $514 \pm 143 * * * \# \#^{\dagger+\dagger}$ & $<0.001$ \\
\hline MVPA/light PA ratio & $0.63 \pm 0.25$ & $0.32 \pm 0.12 * * *$ & $0.46 \pm 0.12 * \# \#$ & $0.29 \pm 0.16 * * *^{t++}$ & $<0.001$ \\
\hline AEE & $2328 \pm 1005$ & $2444 \pm 1332$ & $2555 \pm 954$ & $2052 \pm 1176 * \#^{+\dagger}$ & 0.035 \\
\hline Self-reported sports time (h/week) (b) & $8.50 \pm 3.1$ & $6.80 \pm 2.9 *$ & $8.30 \pm 3.4 \#$ & $3.17 \pm 2.3^{* * *} \# \# \#^{t \dagger t}$ & $<0.001$ \\
\hline \multicolumn{6}{|l|}{ Cardiometabolic } \\
\hline Systolic blood pressure (mmHg) & $114 \pm 10$ & $118 \pm 13$ & $121 \pm 12$ & $122 \pm 9$ & 0.004 \\
\hline Diastolic blood pressure $(\mathrm{mmHg})$ & $68 \pm 7$ & $70 \pm 9$ & $73 \pm 8$ & $74 \pm 8$ & 0.052 \\
\hline HDL-cholesterol (mmol/L) & $1.23 \pm 0.25$ & $1.09 \pm 0.22$ & $0.97 \pm 0.19 * \# \#$ & $0.95 \pm 0.21 * * \#$ & $<0.001$ \\
\hline Triglycerides (mmol/L) & $1.08 \pm 0.59$ & $1.10 \pm 0.54$ & $1.34 \pm 0.55$ & $1.37 \pm 0.62$ & 0.030 \\
\hline LDL-cholesterol (mmol/L) & $2.66 \pm 0.90$ & $2.36 \pm 0.42$ & $2.64 \pm 0.79$ & $2.77 \pm 0.98$ & 0.278 \\
\hline Total cholesterol (mmol/L) & $4.10 \pm 1.02$ & $3.67 \pm 0.52$ & $3.88 \pm 0.85$ & $4.00 \pm 1.07$ & 0.237 \\
\hline Apolipoproteine A (g/L) & $1.41 \pm 0.20$ & $1.24 \pm 0.17 * *$ & $1.23 \pm 0.13 * *$ & $1.23 \pm 0.14 * *$ & $<0.001$ \\
\hline Apolipoproteine B (g/L) & $0.64 \pm 0.22$ & $0.68 \pm 0.11$ & $0.78 \pm 0.19 * \#$ & $0.83 \pm 0.25 * \#$ & 0.026 \\
\hline $\mathrm{HsCRP}(\mathrm{mg} / \mathrm{L})$ & $1.56 \pm 0.85$ & $1.52 \pm 1.97$ & $2.50 \pm 2.42$ & $2.33 \pm 2.56$ & 0.380 \\
\hline Fasting glucose (mmol/L) & $5.37 \pm 0.47$ & $5.41 \pm 0.50$ & $5.70 \pm 0.68 * \#$ & $5.75 \pm 0.62 * \#$ & 0.028 \\
\hline Fasting insulin (mUI/L) & $17.92 \pm 9.68$ & $20.48 \pm 12.86$ & $28.83 \pm 15.0 * \#$ & $29.02 \pm 13.46 * \#$ & $<0.001$ \\
\hline
\end{tabular}


HOMA-IR

OGTT Glucose at $120 \mathrm{~min}(\mathrm{mmol} / \mathrm{L})$

OGTT Insulin at $120 \mathrm{~min}(\mathrm{mUI} / \mathrm{L})$

Metscore (Z-score)

$\begin{array}{c:c:c:c:c}4.20 \pm 2.69 & 4.92 \pm 3.15 & 7.43 \pm 4.71 * * * \# \# & 7.50 \pm 3.78 * * * \# \# & <0.001 \\ 1.18 \pm 0.29 & 1.19 \pm 0.30 & 1.32 \pm 0.40 & 1.32 \pm 0.35 & 0.154 \\ 69.1 \pm 44.53 & 69.1 \pm 58.3 & 109.1 \pm 71.3 & 110.1 \pm 99.0 & 0.056 \\ -0.43 \pm 0.53 & -0.19 \pm 0.53 & 0.28 \pm 0.64 * \# & 0.35 \pm 0.40 * * \# \# & <0.001\end{array}$

AEE: average energy expenditure ; BMI: body mass index; BP: blood pressure ; hsCRP: high sensitive C-reactive protein ; FFM: fat free mass; FM: fat mass; HC: hip circumference; HDL: high-density lipoprotein; HOMA-IR: homeostasis model assessment of insulinresistance; IR: insulinresistance; LDL: low density lipoproprotein; LPA: light physical activity; MPA: moderate physical activity; MVPA: moderate to vigorous physical activity; OGTT: oral glucose tolerance test; PA: physical activity; VAT: visceral adipose tissue; VPA: vigorous physical activity; SAT: subcutaneous adipose tissue; WC: waist circumference

Different from SED-MVPA+:* $p<0.05 ; * * p<0.01 ; * * * p<0.001$

Different from SED-MVPA- :\# $p<0.05$; \#\# $p<0.01$; \#\#\# $p<0.001$

Different from SED+MVPA+ ; ${ }^{\dagger} p<0.05 ;{ }^{\dagger \dagger} p<0.01 ; \dagger \dagger p<0.001$

(a) Self-reported sports time ( $h /$ week): SED-/MVPA+: $n=26 ; S E D-/ M V P A-: n=29 ; S E D+/ M V P A+: n=24 ; S E D+/ M V P A-: n=27$ 